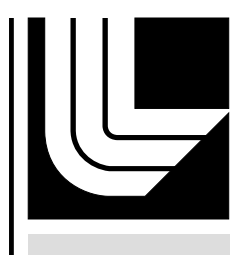

LAW RENCE LIVERMORE N A T IO N A L LABORATORY

\title{
UCRL-TR-210556
}

TEM verification of the <111>-type 4-arm multi-junction in [001]-Mo single crystals

L. Hsiung

March 15, 2005 
This document was prepared as an account of work sponsored by an agency of the United States Government. Neither the United States Government nor the University of California nor any of their employees, makes any warranty, express or implied, or assumes any legal liability or responsibility for the accuracy, completeness, or usefulness of any information, apparatus, product, or process disclosed, or represents that its use would not infringe privately owned rights. Reference herein to any specific commercial product, process, or service by trade name, trademark, manufacturer, or otherwise, does not necessarily constitute or imply its endorsement, recommendation, or favoring by the United States Government or the University of California. The views and opinions of authors expressed herein do not necessarily state or reflect those of the United States Government or the University of California, and shall not be used for advertising or product endorsement purposes.

This work was performed under the auspices of the U.S. Department of Energy by University of California, Lawrence Livermore National Laboratory under Contract W-7405-Eng-48. 


\section{TEM verification of the <111>-type 4-arm multi-junction in [001]-Mo single crystals}

\section{Luke Hsiung}

\section{Objective}

To investigate and verify the formation of <111>-type 4-arm multi-junction by the dislocation reaction of $1 / 2[111][\mathbf{b} 1]+1 / 2[\overline{1} 1 \overline{1}][\mathbf{b} 2]+1 / 2[\overline{1} \overline{1} 1]$ [b3] $=1 / 2[\overline{1} 11]$ [b4], which has recently been discovered through computer simulations conducted by Vasily Bulatov and his colleagues.

\section{Approach}

TEM foils were sliced parallel to the (101) plane of a compress-deformed [001]-Mo single crystal (total strain: $1 \%$, strain rate: $1.0 \mathrm{~s}^{-1}$ ), the foil thinning procedure was completed using twin-jet electropolishing techniques. A $\mathbf{g}$ (reflection vector) $\bullet \mathbf{b}$ (Burgers vector) experiment, i.e. the $\mathbf{g} \cdot \mathbf{b}=0$ contrast invisible criterion, was employed to verify the Burgers vector of individual dislocation.

\section{Technical highlight}

A typical result of the $\mathbf{g} \cdot \mathbf{b}$ experiment for verifying the <111>-type 4-arm junction is shown in Figs. 1 - 3. The first two arms of $\mathbf{b 1}$ and $\mathbf{b} 2$ dislocations can be unambiguously identified (Fig. 1) using two reflection vectors: [12 $\overline{1}$ ] and [121], which are available in the [101]-zone diffraction pattern. Although the contrast of b3 and b4 dislocations become invisible using the [101] reflection vector available in the [101]-zone pattern [Fig. 2 (b)], they can not be individually distinguished. In order to identify b3 and b4 dislocations individually, the [ $\overline{2} 01]$-zone diffraction pattern has been used. Here, b3 and b4 dislocations can be identified unambiguously (Fig. 3) using reflection vectors: [ $\overline{1} \overline{2}$ ] and [1 $\overline{1}$ ], which are available in the $[\overline{2} 01]$-zone diffraction pattern.

(a)

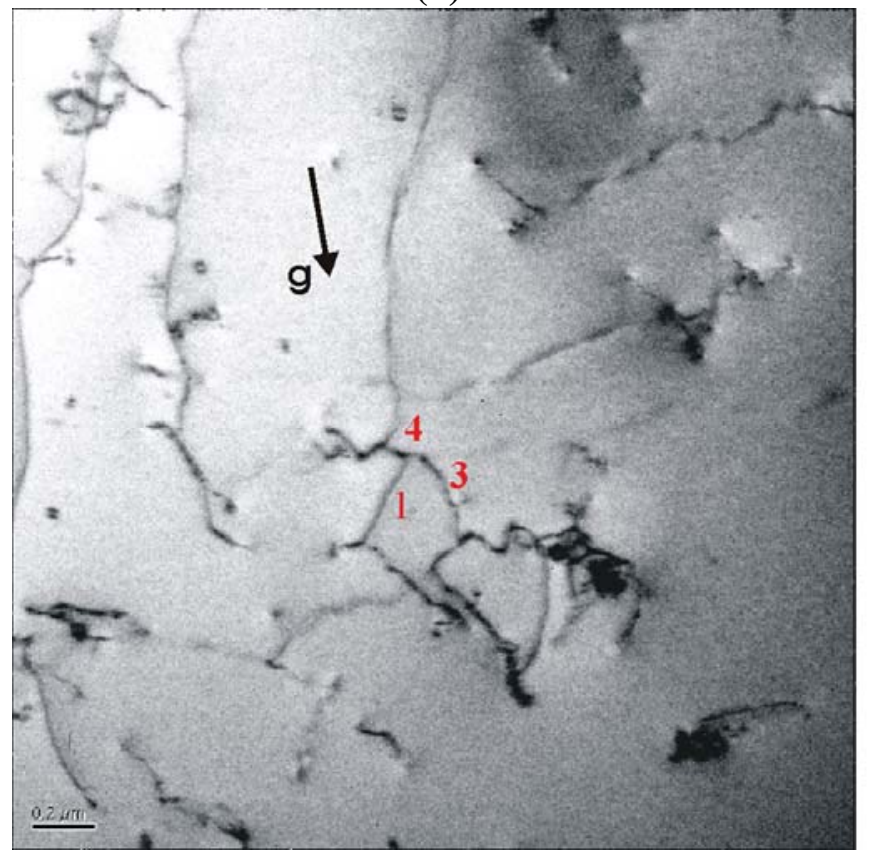

(b)

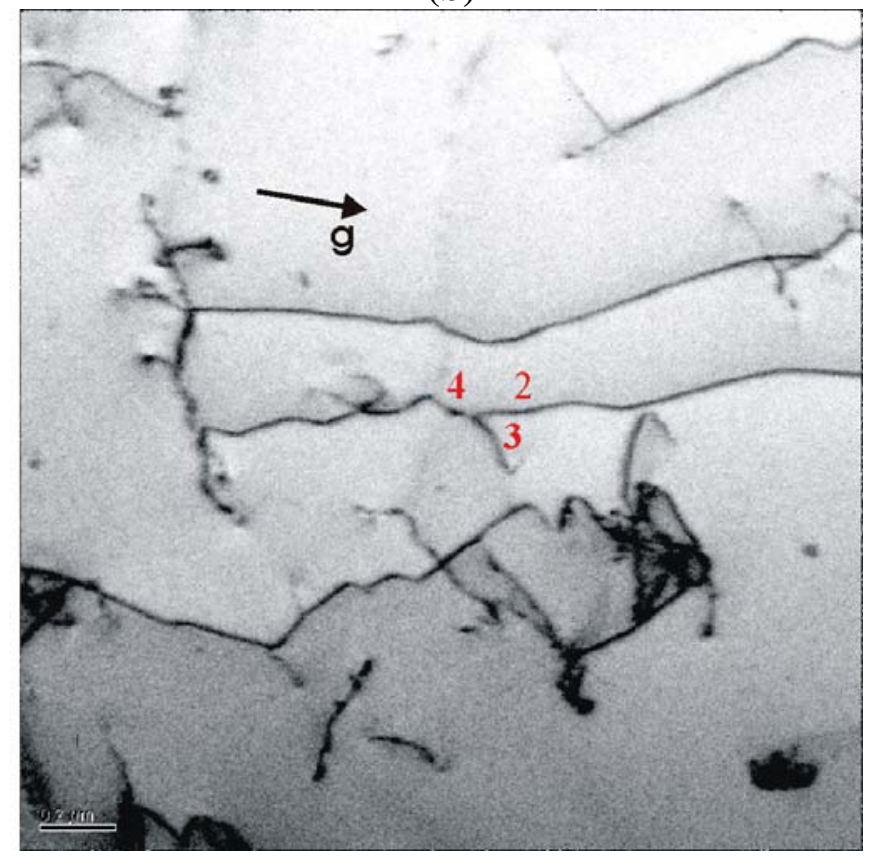

Fig. 1. (a) $\mathbf{Z}$ (zone axis) $\approx$ [101], $\mathbf{g}=[121], 1 / 2[\overline{1} 1 \overline{1}]$ [b2] is invisible; (b) $\mathbf{Z} \approx[\overline{101}], \mathbf{g}=[\overline{1} 2 \overline{1}]$, $1 / 2[111][\mathbf{b 1}]$ is invisible. 
(a)

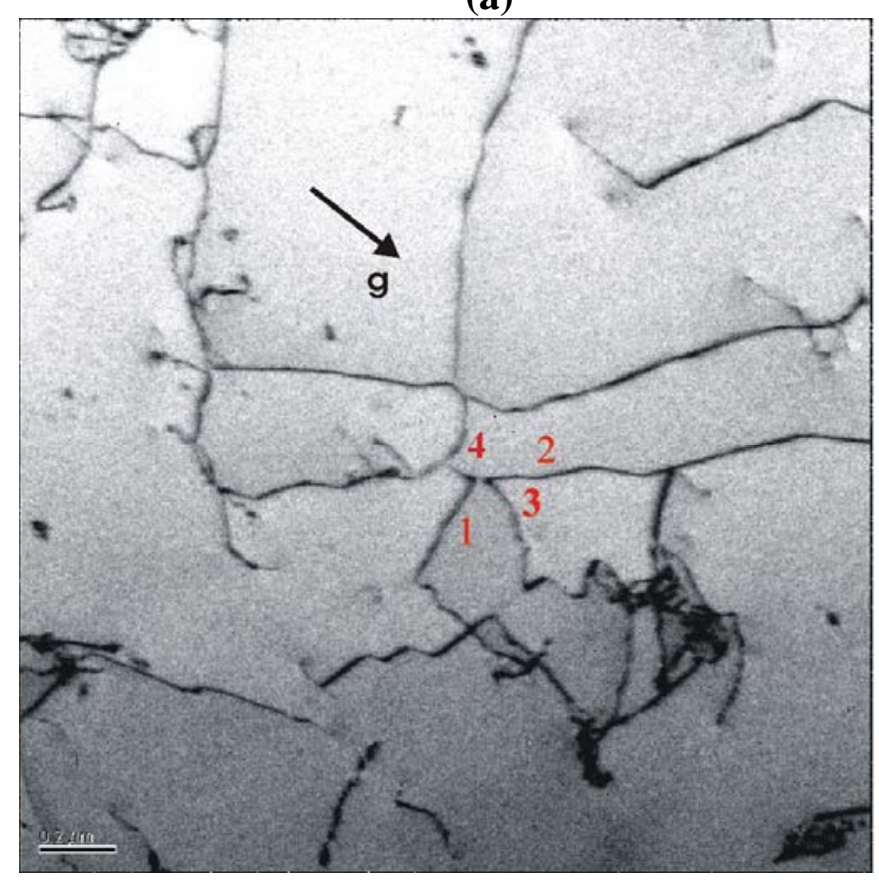

(b)

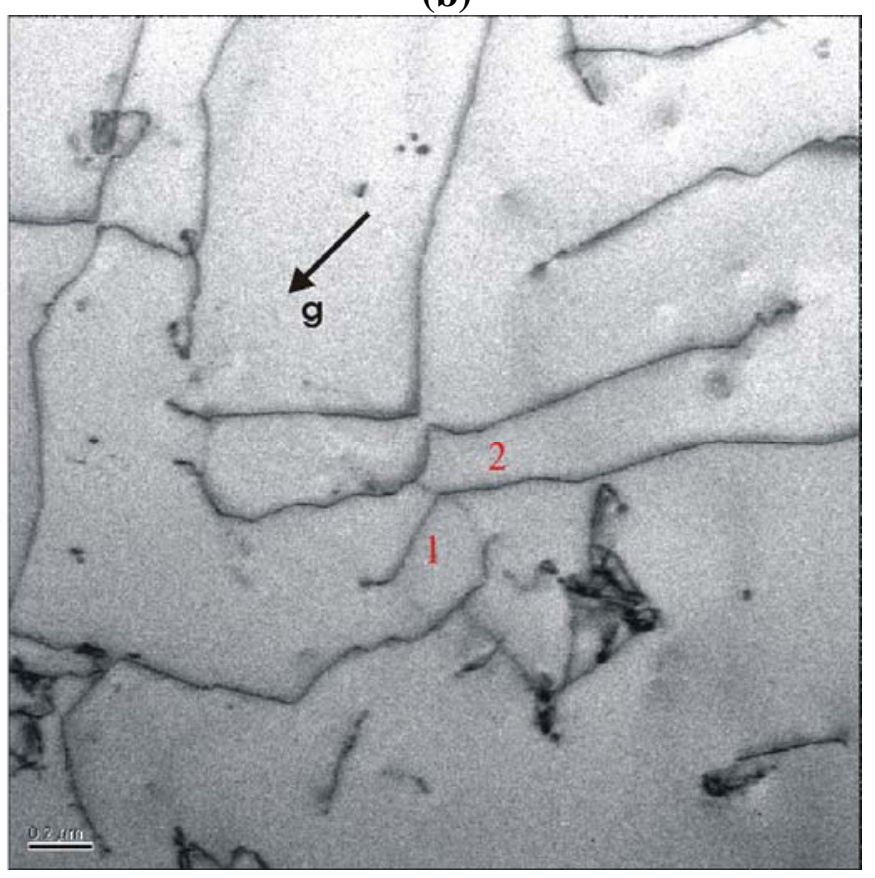

Fig.2. (a) $\mathbf{Z} \approx$ [101], $\mathbf{g}=$ [020], dislocations of all four burgers vectors are visible; (b) $\mathbf{Z} \approx[\overline{101}], \mathbf{g}=$ [101], both $1 / 2[\overline{1} \overline{1} 1]$ [b3] and $1 / 2[\overline{1} 11]$ [b4] are invisible (or have a faint contrast).

(a)

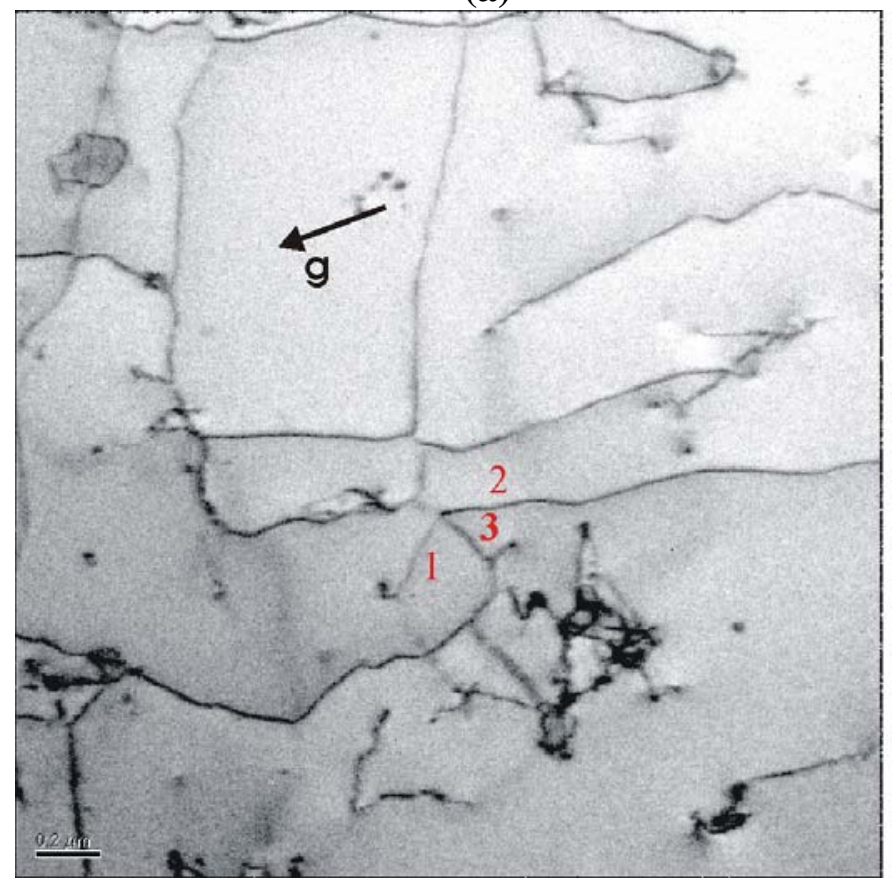

(b)

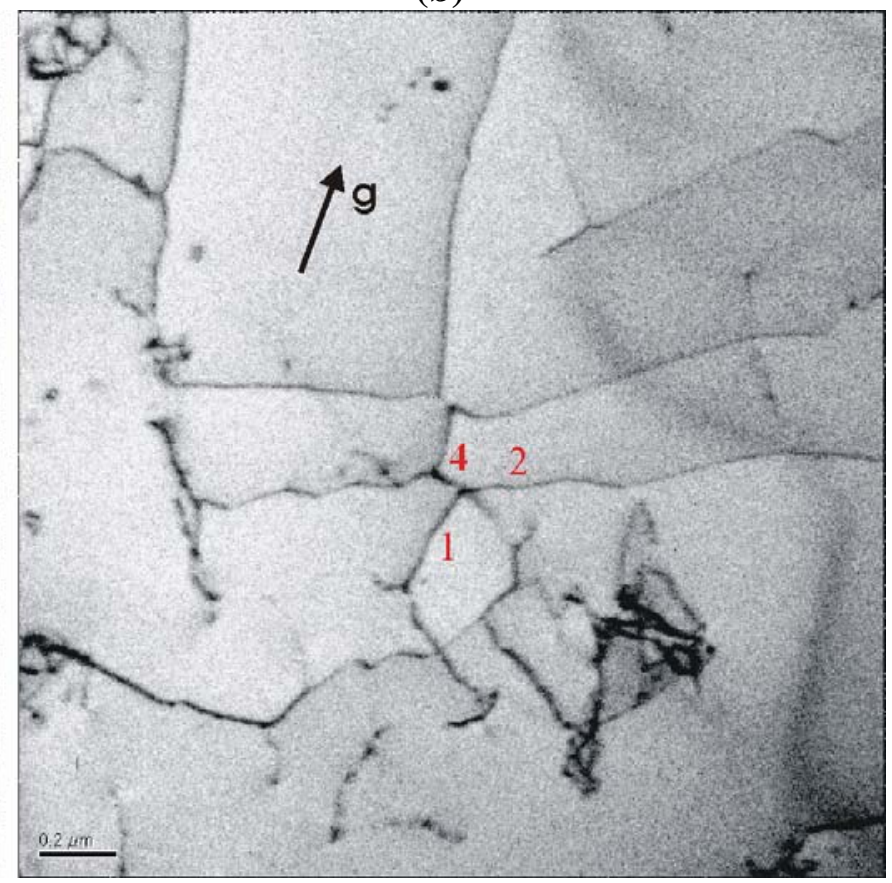

Fig. 3. (a) $\mathbf{Z} \approx[\overline{2} 01], \mathbf{g}=[1 \overline{1} 2], 1 / 2[\overline{1} 11]$ [b4] is invisible; (b) $\mathbf{g}=[\overline{1} \overline{1} \overline{2}], 1 / 2[\overline{1} \overline{1} 1]$ [b3] is invisible (or has a faint contrast). 